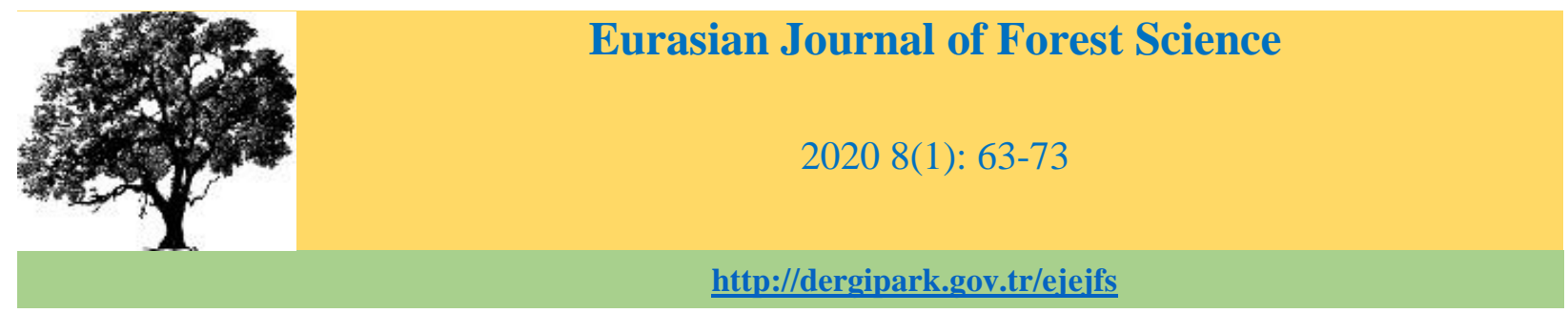

\title{
Evaluating spectral indices for estimating burned areas in the case of Izmir/Turkey
}

\author{
Birsen Kesgin Atak ${ }^{1}$ (D) Ebru Ersoy Tonyaloğlu ${ }^{1 * *}$ \\ ${ }^{1}$ Adnan Menderes University Faculty of Agriculture, Department of Landscape Architecture South Campus \\ 09100 Aydin, Turkey
}

Corresponding author: ebru.ersoy@adu.edu.tr

\begin{abstract}
Mapping and determination of fire damaged areas in an accurate and prompt way is essential for identifying environmental losses caused by fires, post-fire management activities and planning strategies. In this context, this study aims to evaluate the performance spectral indices for discriminating burned and unburned areas in the immediate post-fire environment in the case of Gaziemir, Buca and Karabağlar districts of Izmir metropolitan city where one of the forest fires occurred in the $18^{\text {rd }}$ August 2019. For this, whilst a Sentinel $2 \mathrm{~A}$ (26 $6^{\text {th }}$ August 2019) was used to map burned / unburned areas as the reference dataset, two Landsat 8 satellite images $\left(7^{\text {th }}\right.$ and $28^{\text {th }}$ August 2019) were used for the calculation of spectral indices. The spectral indices of normalised difference vegetation index (NDVI), atmospherically resistant vegetation index (ARVI), two versions of normalised burn ratio (NBR and NBR2) and burnt area index (BAI) were calculated for the selected two dates as well as pre-fire and post-fire temporal differences in those indices. For the performance comparison of spectral indices, binary maps of burned and unburned areas were created and separability index (SI) was calculated for pre/post-fire differenced spectral indices. Our results suggest that NBR2, NDVI and ARVI had the highest potential for discriminating burned areas, respectively. Even though the value of separability indices was different from each other where NBR and BAI had the lowest values, that doesn't necessarily mean these indices cannot discriminate burned areas since the separation of burned and unburned areas highly depend on the spatio-temporal circumstances e.g. vegetation types and time lags between image acquisition dates.
\end{abstract}

Keywords: Remote sensing, spectral indices, burned area mapping, Landsat 8, Sentinel 2A.

\section{Introduction}

Forests, one of the most important natural elements of landscapes and one of the most species rich resources, provide a range of ecological, economic, social and cultural functions to all organisms as well as forming habitats to different species. Even though forests occupy almost one third of the Earth's land surface, they capture a higher proportion of solar energy, constitute large cooling islands, contain the largest concentrations of organic material, and act as carbon sinks compared to all other terrestrial and aquatic ecosystems (Gibbs et al. 2007; Chen et al. 2010; Curtis and Gough 2018). However, forests all over the world have been increasingly degraded / disappeared as a result of demand for natural resources, meeting the requirements of growing populations and natural hazards. Forest fires, one of the most important natural disasters in the globalising world, are one of the most prominent disturbance factors that cause the destruction of very large forest areas in a very short time unless necessary precautions are taken.

In Turkey, as in many parts of the world, one of the main factors endangering the future of our forests certainly is forest fires. Whilst forest fires are considered as one of the most important natural 
disasters, they cause many social, economic and environmental problems. Forest fires are one of the dominant disturbances, particularly in the Aegean and Mediterranean regions of Turkey because of human-induced activities or natural conditions (Hernandez et al. 2015; Kavzoglu et al. 2016). According to the 2019 report of the Turkish General of Directorate of Forestry, the total forest area of Izmir metropolitan area was 475,779 ha in 2018 . However, in the same year we have lost a total forest area of 298,94 ha with 167 forest fires (RTGDF 2019) and most of these were due to human-induced activities. During the summer of the year 2019, numerous and dramatic forest fires have been erupted and destroyed forest areas in the Aegean region of Turkey. On the $18^{\text {rd }}$ August 2019, Izmir metropolitan area has experienced a forest fire in its Gaziemir, Buca and Karabağlar districts where an approximate forest area of 5000 ha was affected.

At the landscape scale, forest fires partially or completely affect the structure and patterns of existing vegetation (Veraverbeke et al. 2010; Fairman et al. 2016). However, the evaluation of the adverse effects of fires requires an accurate identification and also mapping of the areas affected / damaged by them. The identification and mapping of burned areas in forests are also essential for fire management and post-fire damage estimations. Existing research recognises the critical role played by satellite images and remote sensing techniques in supporting the knowledge about burned and damaged areas by fires in an accurately and prompt way as an alternative for extensive field sampling (Mitri and Gitas, 2004; Chuvieco et al. 2006; Tran et al. 2018). Additionally, there is a growing body of literature that recognises the importance of spectral indices as a rapid and cost effective way for the identification and mapping of burned areas in forests (Chuvieco et al. 2002; Miller and Thode 2007; Mouillot et al. 2014). The identification and mapping of burned forest areas is generally based on the evaluation of the changes in spectral properties of vegetated areas before and after fire incidents (Veraverbeke et al. 2010; Fornacca et al. 2018). Normalised difference vegetation index (NDVI), atmospherically resistant vegetation index (ARVI), normalised burn ratio (NBR) and burnt area index (BAI) are the most popular spectral indices used to estimate and assess the damage caused by forest fires (Chen et al. 2011; Chuvieco et al. 2002; Boschetti et al. 2010; Kavzoglu et al. 2016).

In this study, we focused on the Gaziemir, Buca and Karabağlar districts of Izmir metropolitan city where forest fires occur frequently during the dry and windy seasons, between May and September. The main aim of this study was to compare the performance of five widely used spectral indices in the case of the forest fire occurred in $18^{\text {th }}$ August 2019 in this area. The following objectives was identified to achieve the main aim of this research: to assess the boundaries of burned and unburned areas with spectral indices and evaluate their correspondence with burned / unburned area borders defined according to object-based image classification of high resolution Sentinel 2A satellite image dated $26^{\text {th }}$ August 2019. Such information is crucial to short-term effects of fires in the immediate post-fire environment, including the time to allocate and prioritise resources in burned forest areas (e.g. as earliest as possible in the most affected forest areas) as well as to minimise the erosion of the ground and helping the recovering of the damaged vegetation.

\section{Material and Methods Study Area}

The study area is located in Gaziemir, Buca and Karabağlar districts of Izmir metropolitan city with elevations ranging between 154 and $957 \mathrm{~m}$ above the sea level (Figure 1). Whilst Izmir metropolitan city is characterised with typical Mediterranean climate, warm and rainy winters, and hot dry summers; its maximum and minimum average monthly temperatures are $28.0^{\circ} \mathrm{C}$ in July and $8.7^{\circ} \mathrm{C}$ in January (TSMS, 2019). The study area is predominantly covered with Mediterranean vegetation elements of Turkish Red Pine (Pinus brutia) and maquis (Nurlu et al. 2013). 


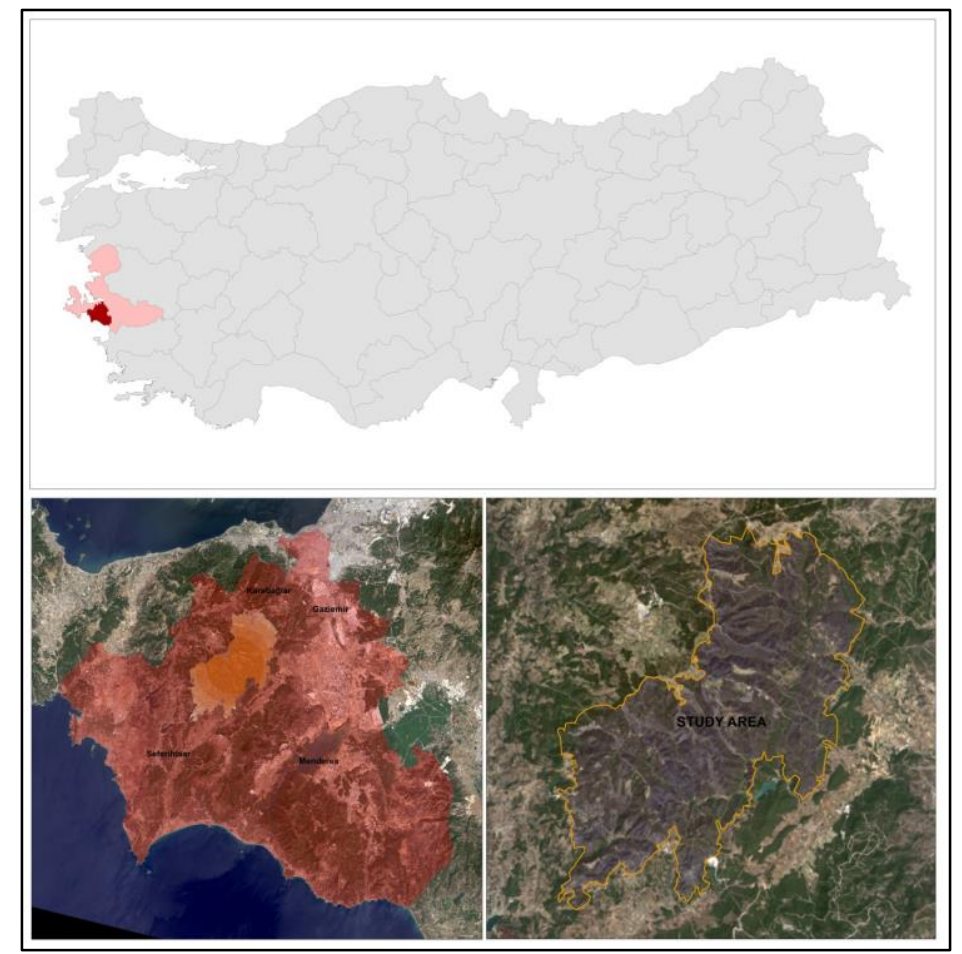

Figure 1. Study area

\section{Material}

In this study, the forest fire on $18^{\text {th }}$ August 2019 in Gaziemir, Buca and Karabağlar district of İzmir was detected on the basis of satellite images. According to the results of damage estimations made by General Directorate of Forestry, after the fire incident, almost 5000 ha forest area has been burned and destroyed. Whilst a Sentinel 2A satellite image $\left(26^{\text {th }}\right.$ August 2019) was used to map burned / unburned areas as the reference dataset, two Landsat 8 satellite images $\left(7^{\text {th }}\right.$ and $28^{\text {th }}$ August 2019) were used for the calculation of spectral indices. Landsat 8 images used for the calculation of spectral indices to find out the pre-fire and post-fire temporal differences are shown below in Figure 2.
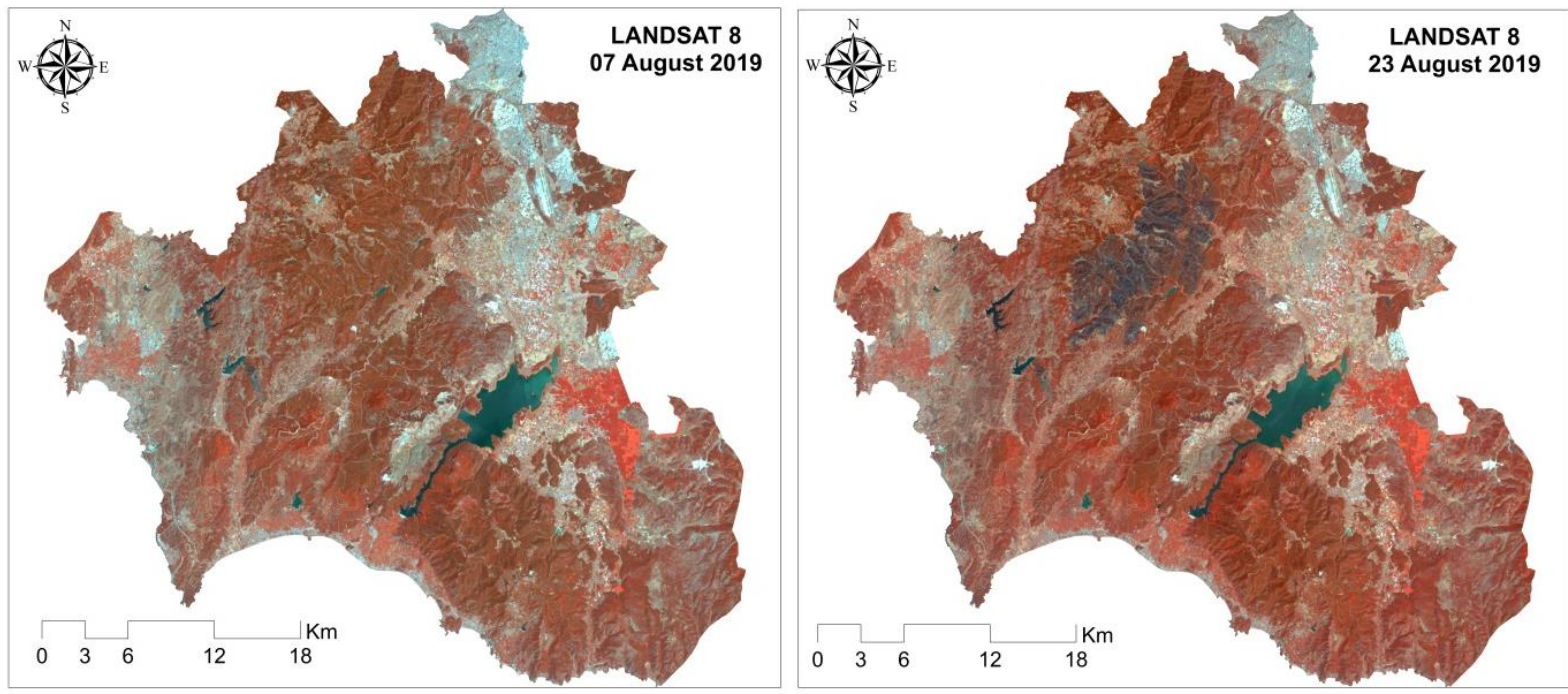

Figure 2. Pre-fire and post-fire Landsat satellite images 
Landsat Satellite images were obtained from the United States Geological Survey (USGS) website. There are two different sensors on the Landsat 8 satellite system: Operational Land Imager (OLI) and Thermal Infrared Sensor (TIRS). 11 different wavelength images are obtained with these sensors. In this study, five spectral bands obtained from OLI sensors were used to detect burned and unburned areas (Table 1).

Table 1. Landsat 8 operational land imagers (OLI) band properties

\begin{tabular}{llll}
\hline Band & $\begin{array}{l}\text { Wavelength range } \\
(\boldsymbol{\mu m})\end{array}$ & $\begin{array}{l}\text { Spatial Resolution } \\
(\mathbf{m})\end{array}$ & $\begin{array}{l}\text { Spectral Width } \\
(\mathbf{n m})\end{array}$ \\
\hline Band 2 - Blue & $0.435-0.451$ & 30 & 6.0 \\
Band 4 - Red & $0.636-0.673$ & 30 & 0.03 \\
Band 5 - Near Infrared (NIR) & $0.851-0.879$ & 30 & 3.0 \\
Band 6 - SWIR 1 & $1.566-1.651$ & 30 & 8.0 \\
Band 7 - SWIR 2 & $2.107-2.294$ & 30 & 18 \\
\hline
\end{tabular}

\section{Methods}

The method of the study was composed of 4 stages including the pre-processing of Landsat 8 satellite images, the calculation of spectral indices on Landsat 8 satellite images, the object-based classification of Sentinel 2A image as the reference data, and the comparison of performance of spectral indices based on separability index.

\section{Pre-processing of Landsat Satellite Images}

The Landsat satellite images were corrected atmospherically and radiometrically to enhance image quality. The original digital numbers of Landsat 8 bands were converted to radiance values using the procedure and coefficient values proposed by Chander et al. (2003).

\section{Object-based Classification of Sentinel 2A Image}

Object based classification of high resolution satellite images is a promising approach for forest fire mapping process, if the most appropriate segmentation parameters are applied. The baseline data source for reference burned / unburned area mapping processes was Sentinel 2A satellite image dated $26^{\text {th }}$ August 2019. Object-based classification of Sentinel 2A satellite image was carried out in eCognition Developer 64 software applying a multi-resolution segmentation and the nearest neighbour supervised classification method. During the multi-resolution segmentation process, pixels of the satellite image are segmented into objects by region-merging technique to form meaningful objects (Pillai et al. 2005; Mathieu et al. 2007). For the multi-resolution segmentation, whilst the scale parameter was set to 15 , shape and compactness were set to 0.2 and 0.7 , respectively. After segmentation stage, training samples were selected from burned and unburned areas and the nearest neighbour supervised classification method.

\section{Calculation of Spectral Indices}

Five widespread spectral indices (NDVI, NBR, NBR2, BAI and ARVI) were calculated from Landsat 8 satellite images to determine the amount of burned and unburned areas (Table 2).

The basic principles of these indices are based on the spectral behaviour of surface characteristics on different spectral wavelengths. For example, the near infrared (NIR) and red (R) wavelengths of the electromagnetic spectrum has a potential for estimating vegetation functioning. In the NIR region of the spectrum, leaf scattering is high due to higher radiation from the canopy in the healthy vegetation structure. 
Table 2. Spectral indices calculated in this study

\begin{tabular}{|c|c|c|c|}
\hline Variable & Abbreviation & Formula & Reference \\
\hline $\begin{array}{l}\text { Normalized difference } \\
\text { vegetation index }\end{array}$ & NDVI & ( NIR - RED) / (NIR + RED) & Tucker, 1979 \\
\hline $\begin{array}{l}\text { An atmospherically } \\
\text { resistant vegetation } \\
\text { index }\end{array}$ & ARVI & NIR-RED $-\gamma($ RED-BLUE) $/$ NIR+Red $-\gamma($ Red-Blue $)$ & $\begin{array}{l}\text { Kaufman and } \\
\text { Tanre, } 1992\end{array}$ \\
\hline $\begin{array}{l}\text { The Normalized Burn } \\
\text { Ratio }\end{array}$ & NBR & $(\mathrm{NIR}-\mathrm{SWIR} 2) /(\mathrm{NIR}+\mathrm{SWIR} 2)$ & $\begin{array}{l}\text { Key \& Benson, } \\
2005\end{array}$ \\
\hline $\begin{array}{l}\text { The Normalized Burn } \\
\text { Ratio } 2\end{array}$ & NBR2 & (SWIR1 - SWIR2) / (SWIR1 + SWIR2) & USGS, 2019 \\
\hline $\begin{array}{l}\text { The Burned Area } \\
\text { Index }\end{array}$ & BAI & $1 /(0.1-\mathrm{Red})^{2}+/(0.06-\mathrm{NIR})^{2}$ & $\begin{array}{l}\text { Martin et al., } \\
\text { (1998), } \\
\text { Chuvieco et al., } \\
\text { (2002) }\end{array}$ \\
\hline \multicolumn{4}{|c|}{$\begin{array}{l}\text { For Landsat 8: RED (Band 4); BLUE (Band2); NIR: Near infrared (Band 5); SWIR1: Short wave infrared (Band 6); SWIR2: } \\
\text { Short wave infrared (Band 7) } \\
\gamma \text { - an atmospheric self-correcting factor was set to } 1 \text { (the aerosol model is not available) }\end{array}$} \\
\hline
\end{tabular}

However, in the R component of the spectrum, high pigment absorption results in lower reflection of radiation. On the other hand, if the vegetation structure gets poorer depending on fire incidents, NIR reflectance gets lower, and its red and mid-infrared reflectance gets higher (Chuvieco and Congalton 1988). The normalized difference vegetation index (NDVI) combines the reflectance in the R and NIR spectral region and as a measure of the amount of vegetation where the lower the ratio values, the more intense damage to vegetation, in other words the more severe impact of the fire. On the other hand, the normalized burn ratio (NBR) represents the healthy chlorophyll content in vegetation, vegetation moisture and water content of soil by combining the NIR with SWIR reflectances. When a fire incident happens, this causes an increase in the radiation reflection in the R and NIR spectral regions, and a decrease in the reflection in the NIR region (Pereira et al. 1999). As a result, the higher ratio values of the NBR express more severe impacts of fire. Additionally, to emphasise the sensitivity of water in vegetation, NBR2 is calculated by modifying SWIR1 band to NIR band which is used in the original NBR index (USGS 2019). The burned area index (BAI) is computed on the basis of the R and NIR spectrums of the multi-temporal images by highlighting the convergence point of the charcoal signal in recently burned regions. The spectral values of this convergence point (NIR reflectance 0.06 and $\mathrm{R}$ reflectance 0.1 ) were based on literature (see Martin et al. 2002; Chuvieco et al. 2002). The other index used in this study is the atmospherically resistant vegetation index (ARVI), proposed by Kaufman and Tanre (1992), with the aim of reducing the atmospheric influence on the vegetation signal by considering radiance in the blue band, which is generally the most effected band from the atmospheric scattering.

In order to determine the magnitude of changes caused by a fire, the post-fire images of spectral indices are subtracted from the pre-fire images. The advantage of pre / post-fire differenced indices is in their capability to discriminate clearly unburned sparsely vegetated areas and burned areas (Key and Benson 2005; Hammill and Bradstock 2006).

\section{Calculation of Burned and Unburned Areas and Accuracy Assessment}

After setting the mean values of each pre / post-fire differenced spectral indices as the threshold for classification, binary maps of burned and unburned areas were created. Then the total accuracy of the derived maps and the accuracy of burned areas were calculated in ArcGIS 10.5 using the reference 
burned / unburned map. We also calculated the total area of burned and unburned areas to evaluate the performance of spectral indices in determining the magnitude of changes caused by the fire.

\section{Discrimination of Spectral Sensitivity of Burned Areas}

The separability index (SI) is widely used to evaluate the performance of spectral indices in terms of their capability for the discrimination of burned and unburned areas. It is computed as follows:

$$
M=\frac{|\mu b-\mu u b|}{(\delta b+\delta u b)}
$$

$\mu b$ : mean values of the considered spectral band of the burned; $\mu u b$ : the mean values of the considered spectral band of unburned area; $\delta b$ : the standard deviations of spectral values of the burned area; $\delta u b$ : the standard deviations of spectral values of the unburned area.

Higher separability index values indicate that the given spectral index has a strong separability attribute whereas lower values reflect that the discrimination of burned and unburned pixels are not as good as the higher SI values. For the calculation of separability index, we used Zonal statistics tool in ArcGIS 10.5. With this tool, the mean and standard deviation values of burned and unburned areas in spectral indices were obtained using the reference burned / unburned map.

\section{Results}

Based on the object-based classification of Sentinel 2A image, we obtained the map of fire representing burned and unburned areas (Figure 3). The overall accuracy of the burned / unburned map was 87,12 with a kappa value of 81,10 . Tran et al (2018) claim that kappa values greater than 0,77 represent substantial agreement for the accuracy of burned areas. So, our result showed that the accuracy of our burned / unburned map is quite good. The fire affected an approximate area 7625 ha including damaged / burned and unburned areas. Our results showed that $\% 78,7$ of the total area was burned (around 6000 ha).

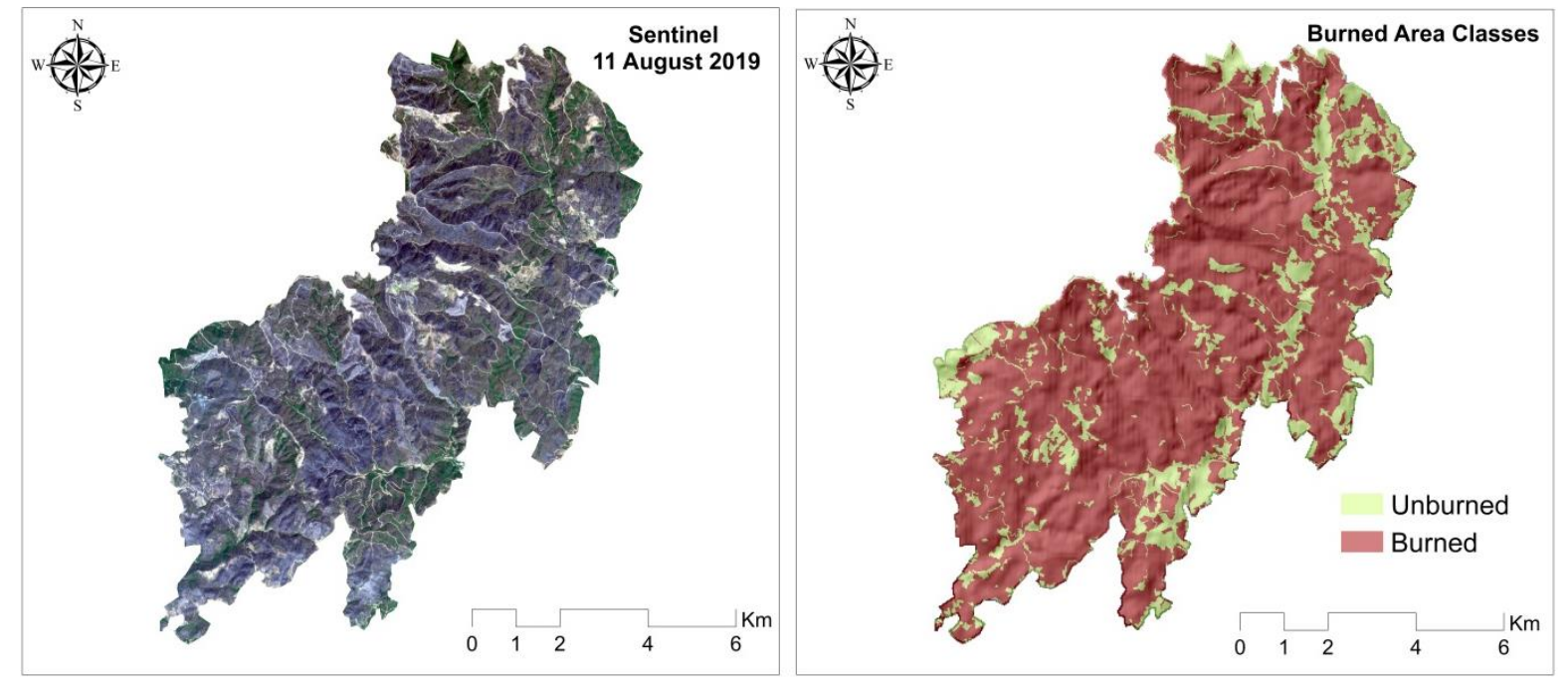

Figure 3. Object-based classification of Sentinel 2A satellite image

The images of spectral indices are shown in Figure 4. 


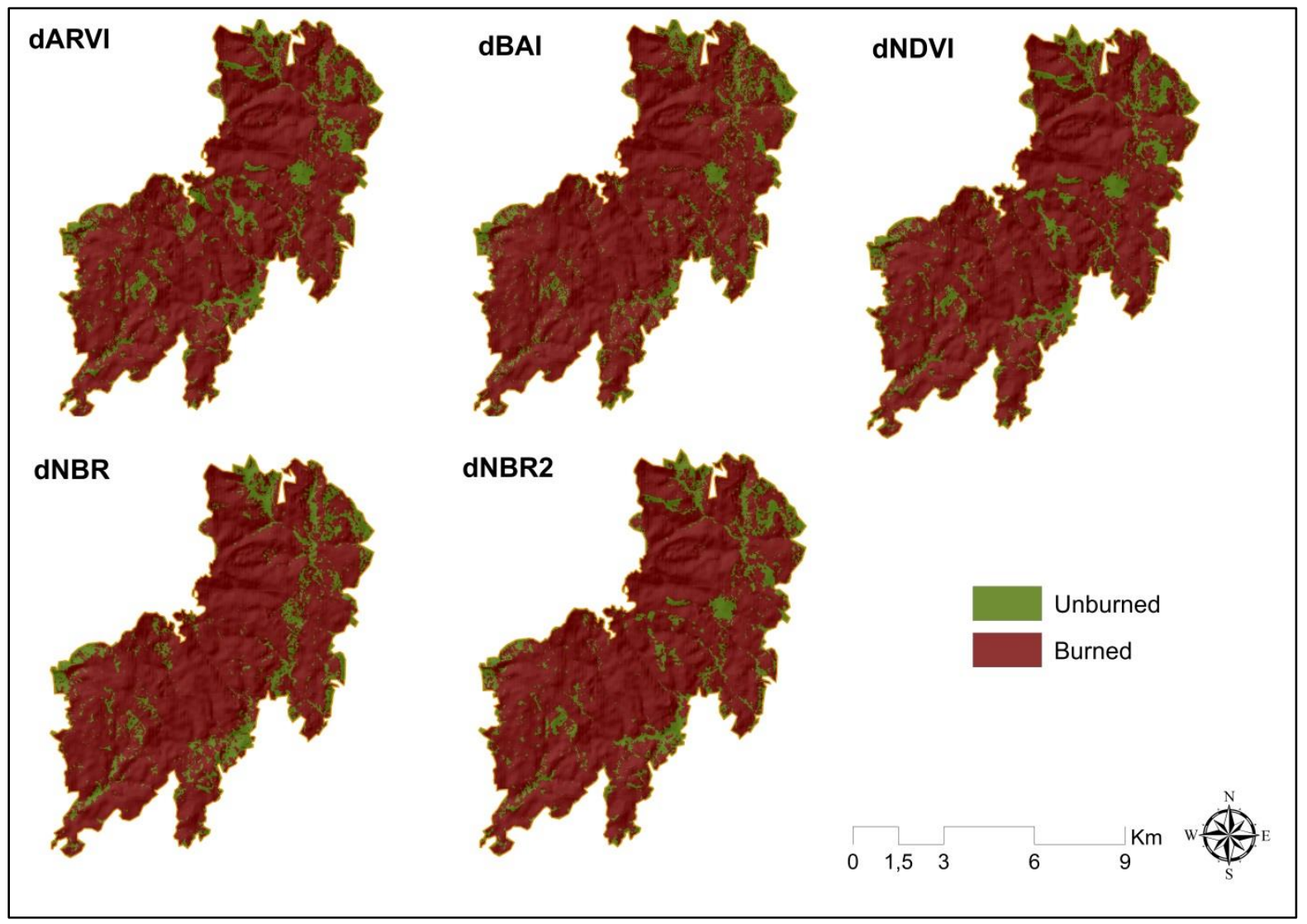

Figure 4. Classification of spectral indices

Threshold values for each spectral index for the classification of burned and unburned areas after the fire were based on the mean and standard deviation values of each index (Table 3).

Table 3. The total area of burned and unburned area obtained from spectral indices

\begin{tabular}{lllllll}
\hline & \multicolumn{7}{c}{ Area (Ha) } \\
\hline Classes & dNDVI & dARVI & dBAI & dNBR & dNBR2 & $\begin{array}{l}\text { References } \\
\text { data }\end{array}$ \\
\hline Unburned & 1422,99 & 1203,84 & 1220,4 & 1199,7 & 1330,74 & 1622,52 \\
Burned & 6203,88 & 6423,03 & 6406,47 & 6427,17 & 6296,13 & 6002,37 \\
\hline
\end{tabular}

The accuracy of each classification is shown in Table 4.

Table 4. Accuracy assessment of each classification for spectral indices

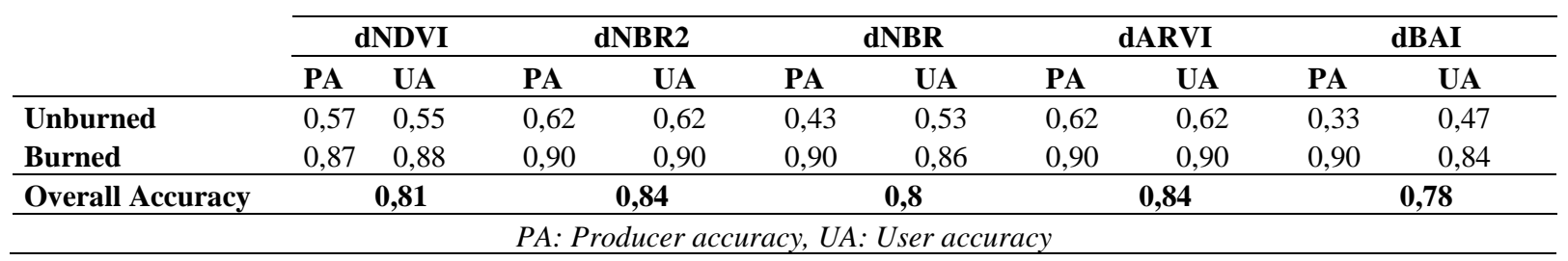

According to the results of accuracy assessments, dNBR2 and dARVI reported the highest overall accuracy $(0,84)$ with quite high producer and user accuracy levels for burned areas. This was followed by dNDVI, dNBR and dBAI. The producer and user accuracy levels of unburned areas for each spectral index were lower than burned areas. This result was partly attributed to the lower number of 
accuracy assessment points assigned to the unburned areas because of its total area within the boundaries of the fire incident. At the same time, the borders of burned and unburned areas were mixed. Based on the burned and unburned areas of reference fire dataset, dNDVI resulted in the closest value for burned areas (6203.88 ha) whereas dARVI had the highest burned area coverage (6423.03 ha).

Tran et al (2018) indicate that best-performing spectral indices of fire severity vary according to the type and group of forests. In our case, we have examined the capability of spectral indices in terms of their potential for discriminating burned and unburned areas. Table 5 shows the results of separability index for spectral indices in terms of their capability for the discrimination of burned and unburned areas.

Table 5. Separability index for spectral indices

\begin{tabular}{llllll}
\hline & dNDVI & dARVI & dBAI & dNBR & dNBR2 \\
\hline MeanB & 0,295 & $-0,227$ & 0,012 & 0,156 & $-0,229$ \\
Mean UB & 0,124 & $-0,1$ & 0,007 & $-0,0006$ & $-0,059$ \\
Std B & 0,121 & 0,089 & 0,005 & 0,121 & 0,109 \\
StdUB & 0,081 & 0,07 & 0,004 & 0,087 & 0,064 \\
\hline difmean/difstd (m seperation index) & 0,847 & 0,799 & 0,556 & 0,753 & 0,983 \\
\hline
\end{tabular}

Our results showed that the best-performing spectral indices in discriminating burned and unburned areas ranged from 0,847 to 0,983 . Based on the values of separability indices for each spectral index, dNBR2 had a strong capability in discriminating burned and unburned areas. This was followed by dNDVI and dARVI indices. Similar to the accuracy assessment of burned and unburned classifications, separability index of $\mathrm{dNBR}$ and $\mathrm{dBAI}$ were the lowest values as an indication of weaker performance to discriminate burned and unburned areas compared to the above-mentioned indices.

\section{Discussion}

Spectral indices offer a rapid and cost effective way for the identification and mapping of burned areas (Miller and Thode 2007; Mouillot et al. 2014). Previous studies have used and compared a variety of spectral indices to map and determine the fire damaged areas in an accurate and prompt way (Boschetti et al. 2010; Kavzoglu et al. 2016). In this regard, this study evaluated the performance of 5 commonly used spectral indices for recently burned areas in terms of their capability for the discrimination of burned and unburned areas in the case of Izmir metropolitan city. For this, total areas of burned and unburned areas in binary maps and their classification accuracies were evaluated together with the differences in the separability index values for the selected spectral indices.

Our results showed that all spectral indices for recently burned areas are valid and valuable tools for separating burned areas from unburned areas at the immediate post-fire assessments in a mountainous region characterised by Mediterranean climate and vegetation. However, whilst dNBR2 spectral index had the highest burned area discrimination ability, dBAI spectral index had the weakest ability for separating burned and unburned areas. In literature, the strong capability of BAI was emphasised in discriminating recently burned areas in particular where the vegetation is mostly covered by woody plants and charcoal rate is high (Chuvieco et al. 2002; Martín et al. 2005; Schepers et al. 2014; Liu et al. 2016). However in our case BAI index had a reverse behaviour because our study area is composed of woody and herbaceous vegetation together (Schepers et al. 2014). Surprisingly, our results have also revealed that dNDVI had a quite strong discrimination ability of burned and unburned areas. This was again due to the presence of woody and herbaceous vegetation together in our study area. 
Even though the value of separability indices were different from each other, where dNBR and dBAI had the lowest values, that doesn't necessarily mean that these indices cannot discriminate burned areas. But, these results can simply be attributed to their capability for distinguishing burned and unburned patches with higher rates of errors compared to the other spectral indices that were used in this study (Fornacca et al. 2018). This study supports evidence from previous research which have demonstrated that the performance and behaviour of spectral indices for the separation of burned and unburned areas highly depend on spatio-temporal circumstances like vegetation types and time lags between image acquisition dates (Fornacca et al. 2018). Despite these promising results, some questions remain about the severity of fire incidents. The results of this study do not explain the occurrence of adverse effects of fire on different vegetation types. So, a further study with more focus on severity of fire on different vegetation types is therefore suggested. There is also abundant room for further progress in monitoring the post-fire forest recovery. To develop a full picture of the identification and mapping of burned areas and their adverse effects on vegetation, additional studies can also be conducted based on these indices, as well as with a combination of data from other high resolution sensors.

\section{References}

Boschetti, M., Stroppiana, D., Brivio, P. A. (2010). Mapping burned areas in a Mediterranean environment using soft integration of spectral indices from high-resolution satellite images. Earth Interactions, 14(17), 1-20.

Chander, G., Markham, B. (2003). Revised Landsat-5 TM radiometric calibration procedures and postcalibration dynamic ranges. IEEE Transactions on geoscience and remote sensing, 41(11), 2674-2677.

Chen, W., Cao, C., He, Q., Guo, H., Zhang, H., Li, R., Zheng, S., Xu, M., Gao, M., Zhao, J. and Li, S. (2010). Quantitative estimation of the shrub canopy LAI from atmosphere-corrected HJ-1 CCD data in Mu Us Sandland. Science China Earth Sciences, 53(1), 26-33.

Chen, X., Vogelmann, J.E., Rollins, M., Ohlen, D., Key, C.H., Yang, L., Huang, C. and Shi, H. (2011). Detecting post-fire burn severity and vegetation recovery using multitemporal remote sensing spectral indices and fieldcollected composite burn index data in a ponderosa pine forest. International Journal of Remote Sensing, 32(23), 7905-7927.

Chuvieco, E., Congalton, R. G. (1988). Mapping and inventory of forest fires from digital processing of TM data. Geocarto International, 3(4), 41-53.

Chuvieco, E., Martin, M. P., Palacios, A. (2002). Assessment of different spectral indices in the red-near-infrared spectral domain for burned land discrimination. International Journal of Remote Sensing, 23(23), 5103-5110.

Chuvieco, E., Riaño, D., Danson, F. M., Martin, P. (2006). Use of a radiative transfer model to simulate the postfire spectral response to burn severity. Journal of Geophysical Research: Biogeosciences, 111(G4).

Curtis, P. S., Gough, C. M. (2018). Forest aging, disturbance and the carbon cycle. New Phytologist, 219(4), 1188-1193.

Fairman, T. A., Nitschke, C. R., Bennett, L. T. (2016). Too much, too soon? A review of the effects of increasing wildfire frequency on tree mortality and regeneration in temperate eucalypt forests. International Journal of Wildland Fire, 25(8), 831-848.

Fornacca, D., Ren, G., Xiao, W. (2018). Evaluating the Best Spectral Indices for the Detection of Burn Scars at Several Post-Fire Dates in a Mountainous Region of Northwest Yunnan, China. Remote Sensing, 10(8), 1196.

Gibbs, H. K., Brown, S., Niles, J. O., Foley, J. A. (2007). Monitoring and estimating tropical forest carbon stocks: making REDD a reality. Environmental Research Letters, 2(4), 045023.

Hammill, K. A., Bradstock, R. A. (2006). Remote sensing of fire severity in the Blue Mountains: influence of vegetation type and inferring fire intensity. International Journal of Wildland Fire, 15(2), 213-226. 
Hernandez, C., Drobinski, P., Turquety, S. (2015). How much does weather control fire size and intensity in the Mediterranean region?. Annales Geophysicae, European Geosciences Union, 2015, 33 (7), 931-939.

Kaufman, Y. J., Tanre, D. (1992). Atmospherically resistant vegetation index (ARVI) for EOS-MODIS. IEEE transactions on Geoscience and Remote Sensing, 30(2), 261-270.

Kavzoglu, T., Erdemir, M. Y., Tonbul, H. (2016). Evaluating performances of spectral indices for burned area mapping using object-based image analysis. In 12th International Symposium on Spatial Accuracy Assessment in Natural Resources and Environmental Sciences (pp. 5-8).

Key, C. H., Benson, N. C. (2005). Landscape assessment: ground measure of severity, the Composite Burn Index; and remote sensing of severity, the Normalized Burn Ratio. FIREMON: Fire effects monitoring and inventory system, 2004.

Liu, W., Wang, L., Zhou, Y., Wang, S., Zhu, J., Wang, F. (2016). A comparison of forest fire burned area indices based on HJ satellite data. Natural Hazards, 81(2), 971-980.

Martín, M. P., Gómez, I., Chuvieco, E. (2006). Burnt Area Index (BAIM) for burned area discrimination at regional scale using MODIS data. Forest Ecology and Management, (234), S221.

Mathieu, R., Aryal, J., Chong, A. (2007). Object-based classification of Ikonos imagery for mapping large-scale vegetation communities in urban areas. Sensors, 7(11), 2860-2880.

Miller, J. D., Thode, A. E. (2007). Quantifying burn severity in a heterogeneous landscape with a relative version of the delta Normalized Burn Ratio (dNBR). Remote Sensing of Environment, 109(1), 66-80.

Mitri, G. H., Gitas, I. Z. (2004). A performance evaluation of a burned area object-based classification model when applied to topographically and non-topographically corrected TM imagery. International Journal of Remote Sensing, 25(14), 2863-2870.

Mouillot, F., Schultz, M. G., Yue, C., Cadule, P., Tansey, K., Ciais, P., Chuvieco, E. (2014). Ten years of global burned area products from spaceborne remote sensing-A review: Analysis of user needs and recommendations for future developments. International Journal of Applied Earth Observation and Geoinformation, 26, 64-79.

Nurlu, Engin, Ü. Erdem, H. Doygun, H. Oğuz, Birsen Kesgin, N. Doygun, Isin Barut, and Eylul Malkoc. (2013). The Effects of Land Cover Change on Natural Ecosystems: The Case of İzmir, Turkey. Journal of Selcuk University Natural and Applied Science, 2(2), 371-378.

Pereira, J. M. (1999). A comparative evaluation of NOAA/AVHRR vegetation indexes for burned surface detection and mapping. IEEE Transactions on Geoscience and Remote Sensing, 37(1), 217-226.

Pillai, R. B., Weisberg, P. J., \& Lingua, E. (2005), Object-oriented classification of repeat aerial photography for quantifying woodland expansion in central Nevada. In $20^{\text {th }}$ Biennial Workshop on Aerial Photography, Videography, and High Resolution Digital Imagery for Resource Assessment, Waslaco, TX, October (pp. 2-6).

Pleniou, M., Koutsias, N. (2013). Sensitivity of spectral reflectance values to different burn and vegetation ratios: A multi-scale approach applied in a fire affected area. ISPRS journal of photogrammetry and remote sensing, 79, 199-210.

RTGDF. (2019). Forestry statistics, Republic of Turkey General Directorate of Forestry. https://www.ogm.gov.tr/ekutuphane/Sayfalar/Istatistikler.aspx ?RootFolder=\%2Fekutuphane\%2FIstatistikler\%2F Ormanc\%C4\%B11\%C4\%B1k\%20\%C4\%B0statistikleri\&FolderCTID=0x012000301D182F8CB9FC49963274E 712A2DC00\&View $=\{$ 4B3B693B-B532-4C7F-A2D0-732F715C89CC $\}$

Schepers, L., Haest, B., Veraverbeke, S., Spanhove, T., Vanden Borre, J., Goossens, R. (2014). Burned area detection and burn severity assessment of a heathland fire in Belgium using airborne imaging spectroscopy (APEX). Remote Sensing, 6(3), 1803-1826.

TSMS. (2019). Turkish State Meteorological Service. Official Statistics. Izmir. https://mgm.gov.tr/eng/forecastcities.aspx?m=IZMIR 
Tran, B., Tanase, M., Bennett, L., Aponte, C. (2018). Evaluation of spectral indices for assessing fire severity in Australian temperate forests. Remote Sensing, 10(11), 1680.

Tucker, C. J. (1979). Red and photographic infrared linear combinations for monitoring vegetation. Remote sensing of Environment, 8(2), 127-150.

USGS. (2019). Landsat Surface Reflectance-Derived Spectral Indices. https://www.usgs.gov/landresources/nli/landsat/landsat-normalized-burn-ratio

Veraverbeke, S., Verstraeten, W. W., Lhermitte, S., Goossens, R. (2010). Evaluating Landsat Thematic Mapper spectral indices for estimating burn severity of the 2007 Peloponnese wildfires in Greece. International Journal of Wildland Fire, 19(5), 558-569.

Submitted: 09.12.2019 Accepted: 09.01.2020 